\title{
Analysis and Design of an Obstacle Detection Radar Transceiver for ISM Band
}

\author{
Bimal Garg, Dauood Saleem
}

Department of Electronics Engineering, Madhav Institute of Technology and Science, Gwalior, India.

Email: bimalgarg@yahoo.com, dauood.saleem@gmail.com

Received April 13 ${ }^{\text {th }}, 2013$; revised April 18 ${ }^{\text {th }}, 2013$; accepted April 25 $5^{\text {th }}, 2013$

Copyright (C) 2013 Bimal Garg, Dauood Saleem. This is an open access article distributed under the Creative Commons Attribution License, which permits unrestricted use, distribution, and reproduction in any medium, provided the original work is properly cited.

\begin{abstract}
Authors designed an obstacle radar transceiver for ISM band. This work is focused on rectangular microstrip transceiver integrated with innovative metamaterial structure at a height of $3.276 \mathrm{~mm}$ from the ground plane. Two rectangular microstrip transceiver is designed for transmitting and receiving purpose. This work is mainly focused on increasing the potential parameters of rectangular microstrip transceiver. RMT along with the proposed innovative metamaterial structure is designed to resonate at $2.259 \mathrm{GHz}$. Simulation results showed that the impedance bandwidth of the RMT is improved by $575 \%$, return loss is reduced by $391 \%$ and efficiency is improved by $28 \%$ by incorporating the proposed innovative metamaterial structure. For verifying that the proposed innovative metamaterial structure possesses negative values of Permeability and Permittivity within the operating frequency range, Nicolson-Ross-Weir method (NRW) has been employed. An op-amp and comparator is used to compare the return loss of transmitting and receiving RMT. An indicator is used to indicate difference of return loss and power of transmitting and receiving rectangular microstrip transceiver. For all simulation purpose, computer simulation technology-microwave studio (CST-MWS) software has been used.
\end{abstract}

Keywords: Rectangular Microstrip Transceiver (RMT); Industrial; Scientific and Medical Radio Band (ISM); Permittivity; Permeability; Nicolson-Ross-Weir (NRW) Approach

\section{Introduction}

Technology supporting safe driving, an information collection infrastructure for sensing road conditions and supplying key information on road conditions to vehicles comprises an important theme for consideration. Development efforts are currently underway to come up with a practical infrastructure of this type. The information collection infrastructure is expected to detect current positions and velocities of obstacles on roads, such as things that have been dropped, or that have fallen on the road, standing or running vehicles. This technology is essential for constructing Smart way. The author has adopted a thematic rather than a chronological approach in Figure 1.

Advanced cruise assist highway system (AHS Smartway, intelligent road) is an infrastructure that realizes Smart cruise with advanced safety vehicle (ASV Smart Car, intelligent vehicle) and smart gateway [1] (Intelligent communications). More specifically, this road is equipped with a variety of information facilities and an administration system to apply the facilities to ITS services. The smart cruise systems are explained in Figures $2 \& 3$.

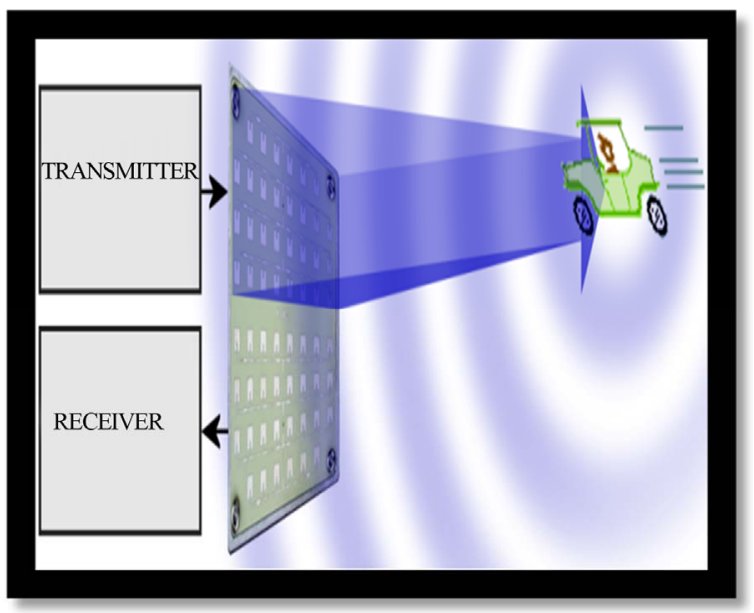

Figure 1. Thematic approach of a rectangular microstrip transceiver. 


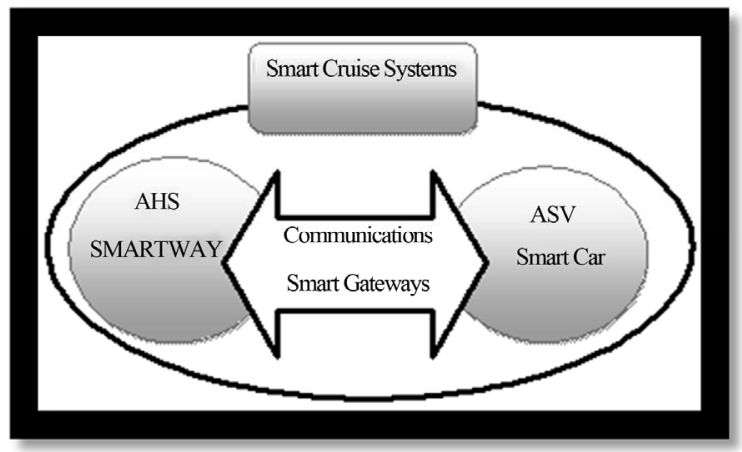

Figure 2. Smart Cruise Systems.

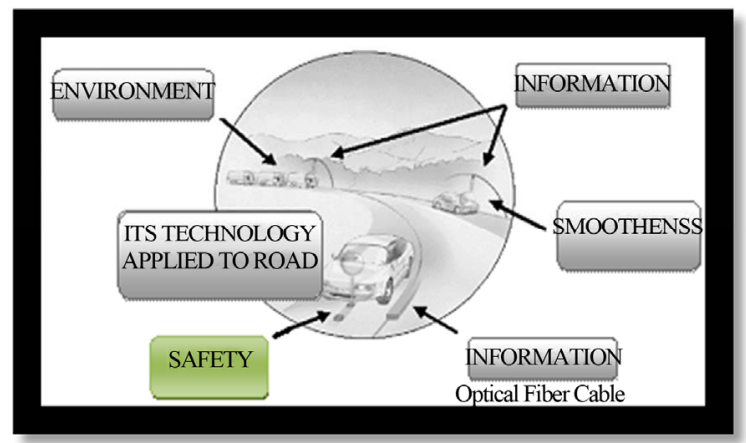

Figure 3. Services provided by Smartway.

Now, what will driving be like in an environment where smart way and smart car begin to exchange information? Let's try to imagine a drive someday when this system is in place.

The radio detection and ranging (RADAR) use rectangular microstrip transceiver to extract information about the target's position. Radar systems transmit signals in form of electromagnetic waves from the transmitter. The signal travels from the source to the target where it is reflected back to the receiver. The difference in the parameters of the transmitted signal and the received signal are then used to extract information about the target. Information that may be obtained includes position, speed, height and size of target. The distance to the target is obtained from the time lapse between the received and the transmitted signal. The size of target is directly proportional to the power of the received signal. For receiving and transmitting purpose the authors used two identical rectangular Microstrip transceivers. This is shown in Figure 4.

Rectangular microstrip transceiver is designed on a dielectric substrate, which is composed of a radiating transceiver on one side and ground plane on the other side as shown in Figure 5.

These are low profile, lightweight, low cost transceivers. In spite of having a lot of advantages these transceivers have some drawbacks like narrow-bandwidth, low gain, high return loss etc. [2]. To overcome trans- ceivers drawbacks several researches have been done on rectangular microstrip transceiver. In this area of research, Victor Veselago [3-4] introduced the theoretical concept of metamaterials. According to the theory of Veselago, these are generally artificial materials used to provide properties, which are not found in readily available materials in nature [5]. For improving the performance of microstrip transceiver J.B. Pendry and his colleagues [6] added more information. They proved that the array of metallic wires can be used to obtain negative permittivity and split ring resonators for negative permeability. On the basis of this information D. R. Smith and his colleagues [7] fabricated a structure in 2001, which was a composition of split ring resonator and thin wire. It had been observed that the structure proposed by them possessed the negative values of permittivity and permeability simultaneously and was named as LHM [8-9].

In this work "Rectangle surrounded by circles and hexagonal" innovative metamaterial structure has been introduced for reducing the return loss and ameliorating the bandwidth and efficiency of the RMT. Metamaterial

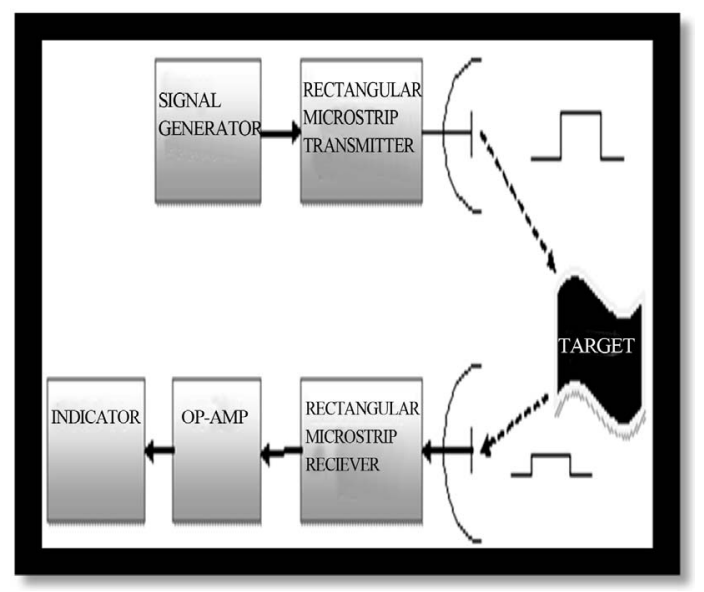

Figure 4. Radar System using rectangular microstrip transceiver.

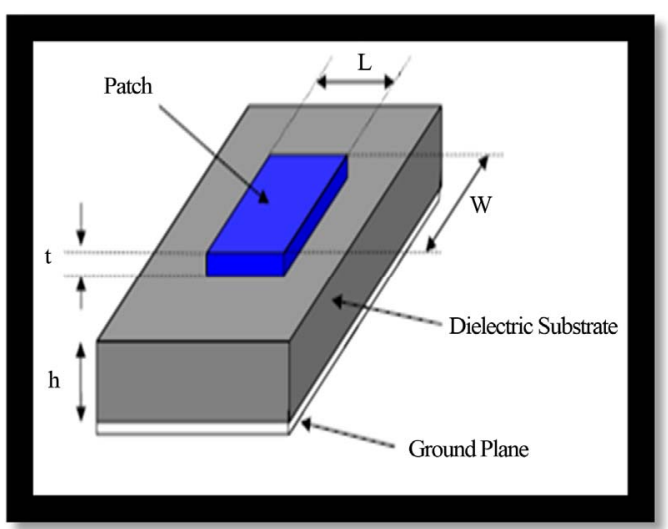

Figure 5. Rectangular microstrip transceiver. 
substrate size variation may affect the microstrip transceiver parameters so that variations in metamaterial substrate have not been done. Along with these outcomes, it has been observed that, this structure satisfies the double negative property within the operating frequency range.

\section{Rectangular Microstrip Transceiver Designing Procedure and Simulation Results of RMT with \& without Innovative Metamaterial Structure}

The RMT parameters are calculated from the formulae given below.

\section{A. Desired Parametric Analysis [10-11]}

Calculation of Width (W)

$$
w=\frac{1}{2 f_{r} \sqrt{\mu_{0} \varepsilon_{0}}} \sqrt{\frac{2}{\varepsilon_{r}+1}}=\frac{C}{2 f_{r}} \sqrt{\frac{2}{\varepsilon_{r}+1}}
$$

where

$c=$ free space velocity of light

$\varepsilon_{r}=$ Dielectric constant of substrate

The effective dielectric constant of the rectangular microstrip transceiver.

$$
\varepsilon_{\text {eff }}=\frac{\varepsilon_{r}+1}{2}+\frac{\varepsilon_{r}-1}{2}\left(\frac{1}{\sqrt{1+\frac{12 h}{w}}}\right)
$$

The actual length of the transceiver $(L)$

$$
L=L_{\text {eff }}-2 \Delta L
$$

where

$$
L_{e f f}=\frac{C}{2 f_{r} \sqrt{\varepsilon_{e f f}}}
$$

Calculation of Length Extension

$$
\frac{\Delta L}{h}=0.412 \frac{\left(\varepsilon_{\text {eff }}+0.3\right)\left(\frac{w}{h}+0.264\right)}{\left(\varepsilon_{\text {eff }}-0.258\right)\left(\frac{w}{h}+0.8\right)}
$$

The Rectangular Microstrip transceiver is designed on FR-4 lossy substrate with $\varepsilon_{r}=4.3$ and height from the ground plane $\mathrm{d}=1.6 \mathrm{~mm}$. The Length and width of RMT are $L=30 \mathrm{~mm}, \mathrm{~W}=36 \mathrm{~mm}$ respectively, which are calculated from the formulae discussed in parametric analysis section. For cut width, cut depth, length of transmission line and width of the feed, some specific values have been chosen to obtain the resonating frequency of the proposed rectangular microstrip transceiver at $2.259 \mathrm{GHz}$. These values can be varied to change the resonating frequency. The parameter specifications of rectangular microstrip transceiver are mentioned in Table 1.
Figure 6 shown below represent dimensional structure of rectangular microstrip transceiver at a resonant frequency $2.259 \mathrm{GHz}$ whose specifications for designing are mentioned above.

In this paper the proposed innovative metamaterial structure is introduced to form the superstate of a rectangular microstrip transceiver. The required specifications of this design are shown in the Figure 7.

Table 1. Rectangular Microstrip Transceiver Specifications.

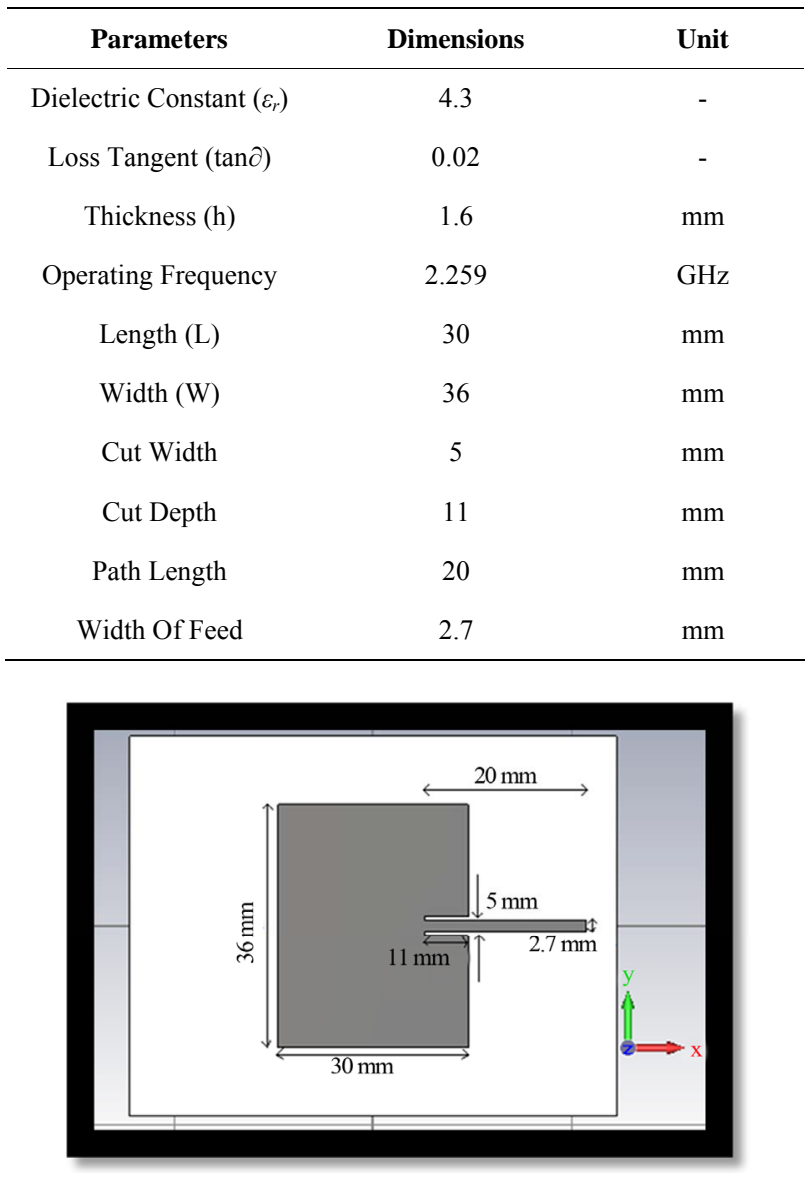

Figure 6. Rectangular microstrip transceiver at $2.259 \mathrm{GHz}$.

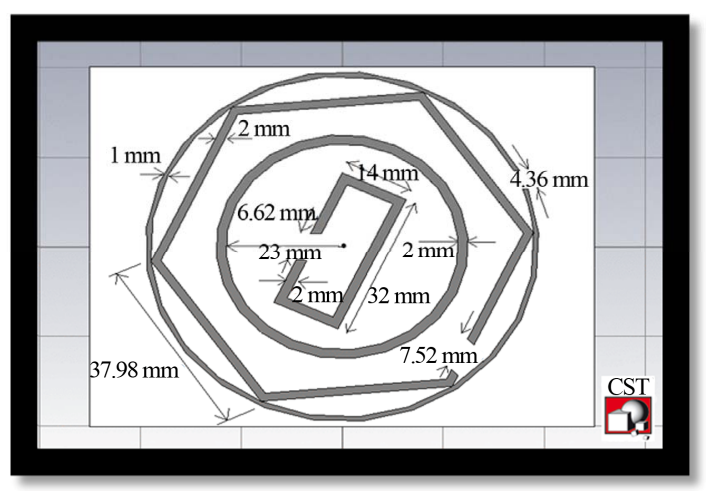

Figure 7. Design of proposed innovative metamaterial structure. 
Rectangular microstrip transceiver with proposed metamaterial is shown below in Figure 8. It shows the accurate position of metamaterial structure over the rectangular microstrip patch antenna. It is more significant that metamaterial structure get accurate position over the patch antenna to radiate in proper order elsewhere some variations in measured results take place from simulation results.

Return loss $S_{11}$ and Impedance Bandwidth of Rectangular Microstrip transceiver is shown in Figure 9. The designed antenna resonates at $2.259 \mathrm{GHz}$. The bandwidth of the antenna can be said to be those range of frequentcies over which the return loss is greater than $-10 \mathrm{~dB}$ (corresponds to a VSWR of 2). Thus the bandwidth of antenna can be calculated from return loss versus frequency plot. The Impedance bandwidth of the simulated patch antenna is $13.8 \mathrm{MHz}$ and resonant frequency is $2.259 \mathrm{GHz}$.

Return loss $S_{11}$ and Impedance Bandwidth of Rectangular microstrip transceiver with proposed metamaterial structure is shown in Figure 10. The bandwidth of the

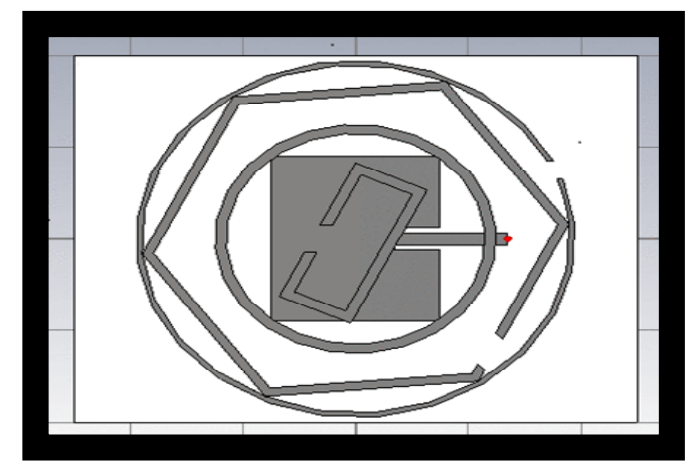

Figure 8. Rectangular microstrip transceiver with proposed innovative metamaterial structure.

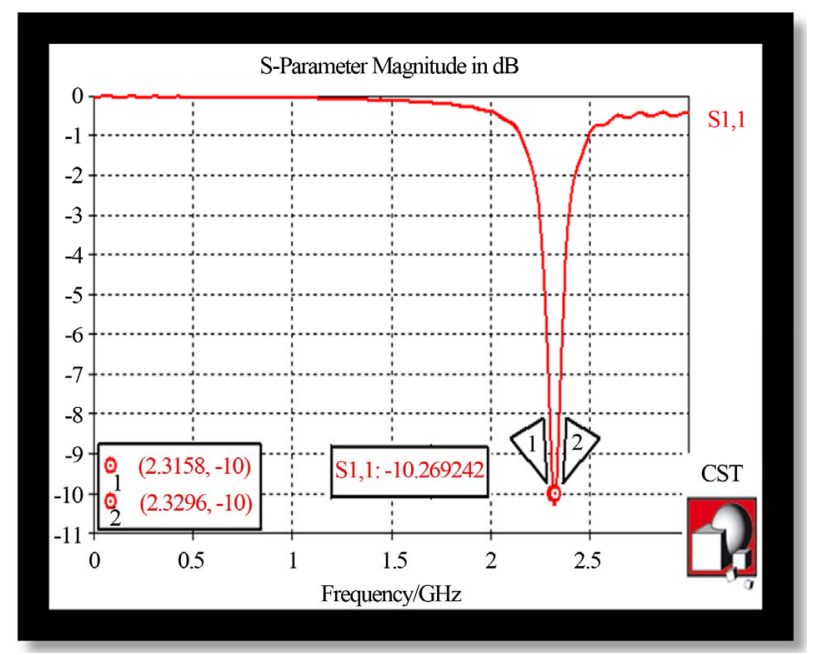

Figure 9. Simulation of Return loss $S_{11}$ and impedance bandwidth of Rectangular microstrip transceiver.

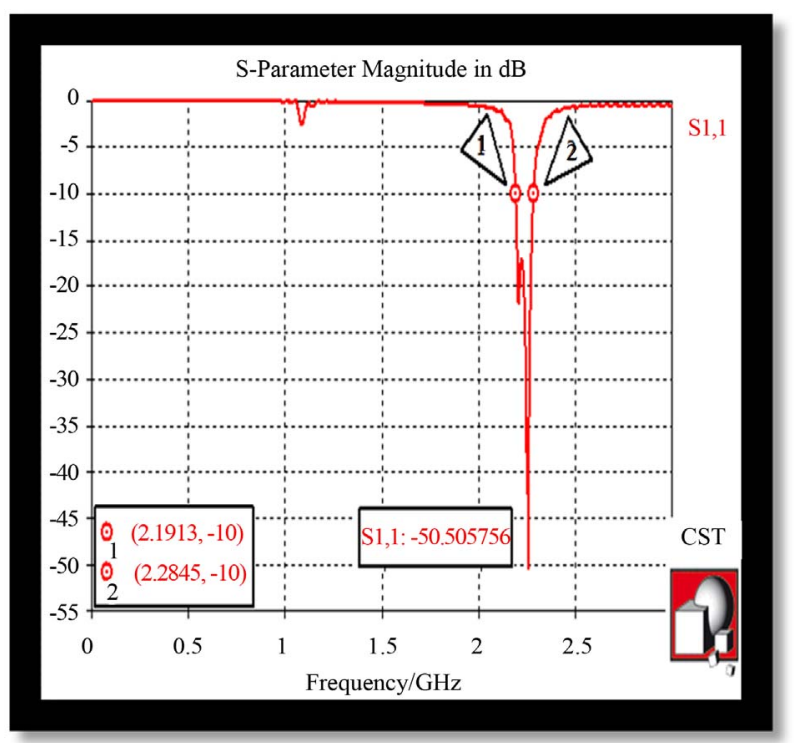

Figure 10. Simulation of Return Loss $S_{11}$ and impedance bandwidth of RMT with proposed metamaterial structure.

antenna can be said to be those range of frequencies over which the return loss is greater than $-10 \mathrm{~dB}$ (corresponds to a VSWR of 2). The bandwidth of the simulated patch antenna is $93.2 \mathrm{MHz}$ and resonant frequency is 2.259 $\mathrm{GHz}(2.1913-2.2845 \mathrm{GHz})$. More negative is the return loss; more is the coupling and therefore more will be the directivity and gain of the proposed antenna in particular direction.

From Figures $9 \& \mathbf{1 0}$ it has been observed that the return loss has significantly reduced by $40.24 \mathrm{~dB}$ and bandwidth has increased by $79.4 \mathrm{MHz}$ by incorporating proposed metamterial structure with RMT. These results are showing that there is amelioration in return loss by $391 \%$ and in bandwidth by $575 \%$ of RMT by incorporating proposed innovative metamaterial structure.

The radiation pattern of a transceiver is generally its most basic requirement because it determines the distribution of radiated energy into the space. Gain depends on directivity and directivity is totally depends on the shape of the radiation patterns of a transceiver. The Radiation Pattern of the RMT operating at $2.259 \mathrm{GHz}$ is shown in Figure 11. This shows that the directivity is $6.993 \mathrm{dBi}$ and efficiency is $-4.984 \mathrm{~dB}$ i.e. $31.73 \%$, whereas Figure 12 shows that the directivity of the RMT with the proposed innovative metamaterial structure that is $7.116 \mathrm{dBi}$ and efficiency is $-3.91 \mathrm{~dB}$ i.e. $40.64 \%$. These results are showing that there is amelioration in efficiency by $28 \%$ and in directivity by $2 \%$ of RMT by incorporating proposed innovative metamaterial structure. Figures $13 \&$ 14 show that power used by transceiver with \& without proposed metamaterial structure.

Figures 15 \& 16 show the E-field and $\mathrm{H}$-field pattern of the proposed rectangular microstrip transceiver along 


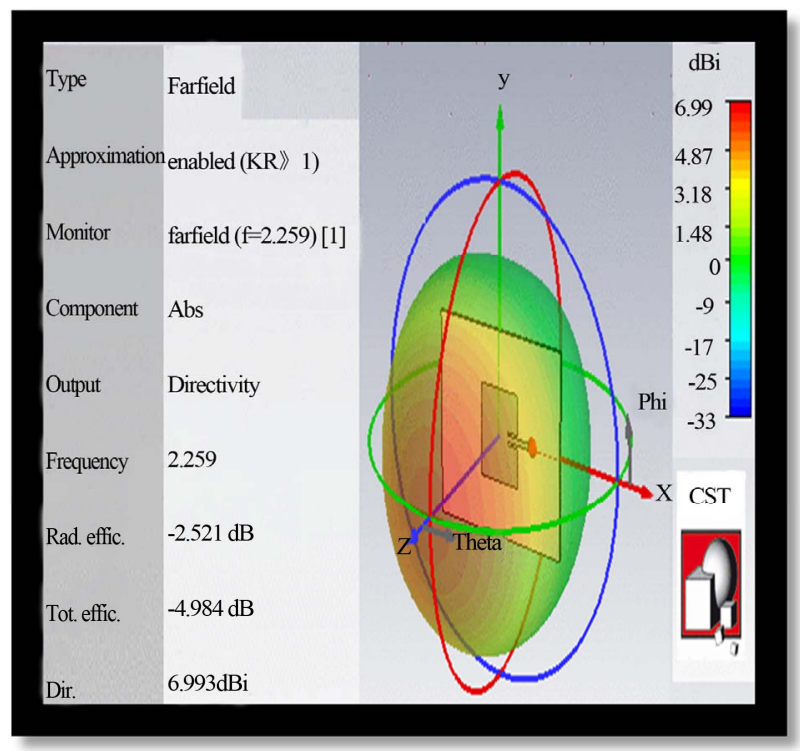

Figure 11. Radiation Pattern of a Rectangular microstrip transceiver.

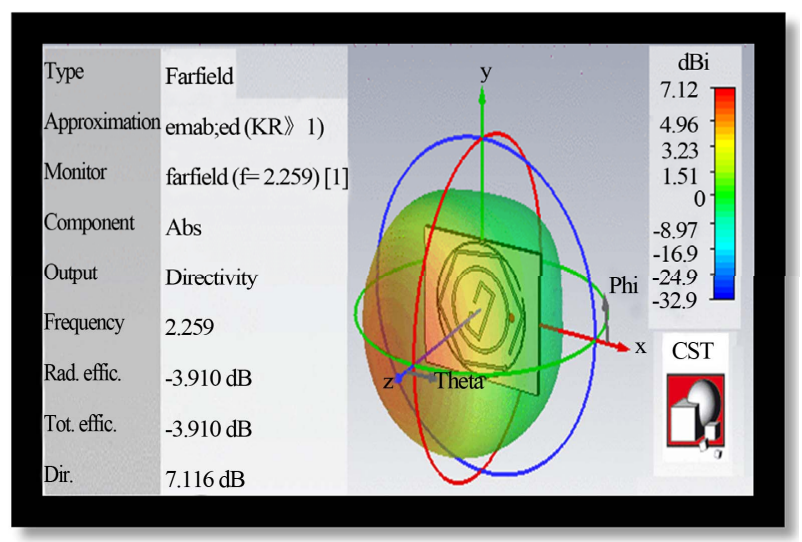

Figure 12. Radiation Pattern of RMT with proposed metamaterial structure.

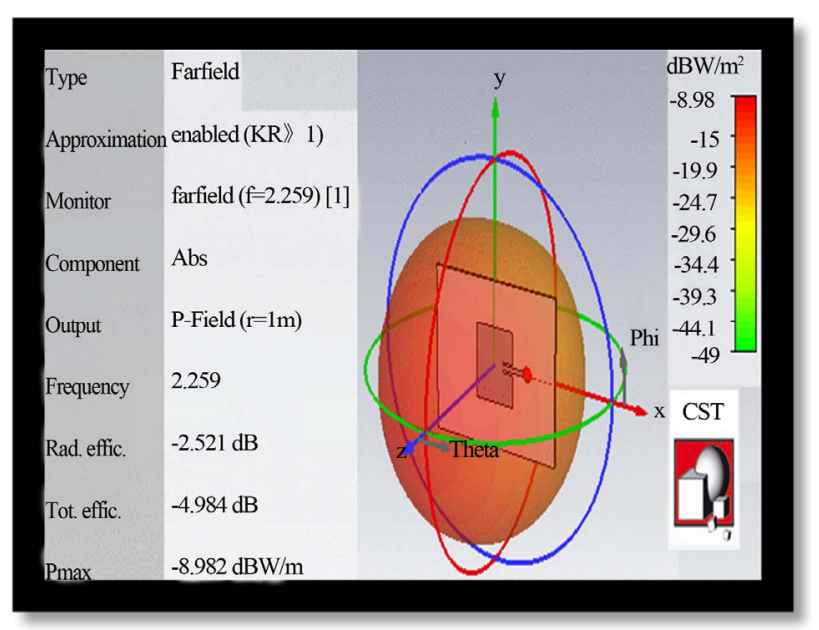

Figure 13. Power Pattern of a Rectangular microstrip transceiver.

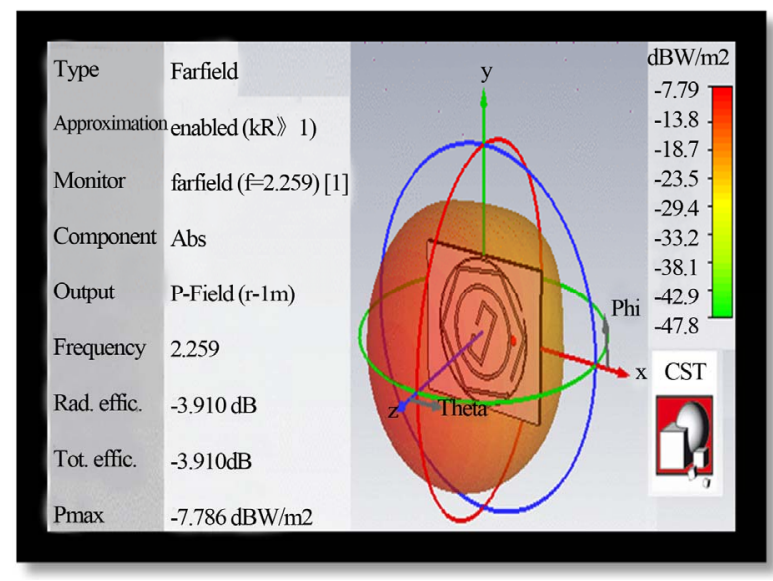

Figure 14. Power Pattern of RMT with proposed metamaterial structure.

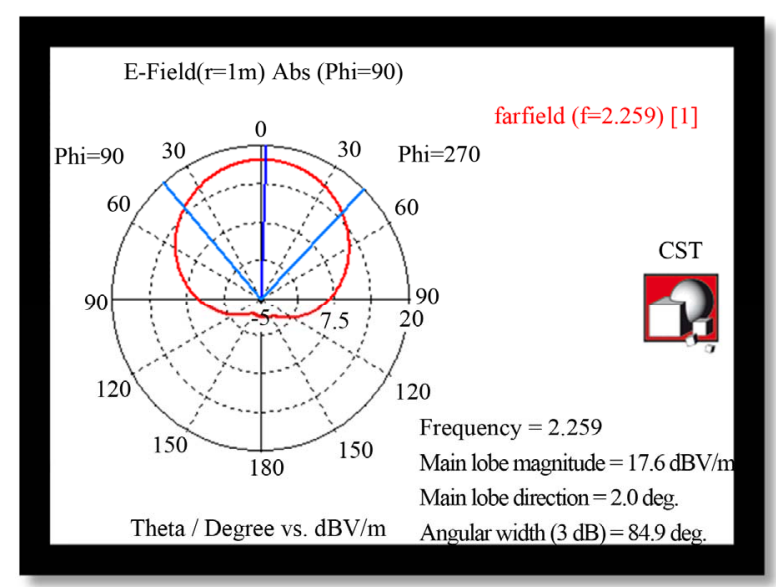

Figure 15. E-Field of RMT with proposed metamaterial structure.

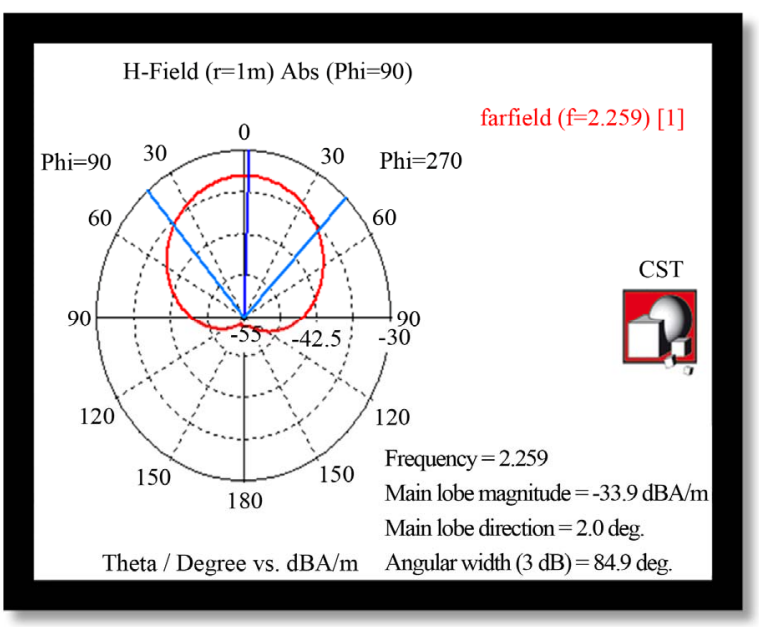

Figure 16. H-Field of RMT with proposed metamaterial structure.

with metamaterial respectively at the operating frequency $2.259 \mathrm{GHz}$, which gives the information about distribu- 
tion of E-field and H-field by the antenna. The magnitude of main lobe for E-field and H-field are $17.6 \mathrm{dBV} / \mathrm{m}$ and $-33.9 \mathrm{dBA} / \mathrm{m}$ respectively and angular width of both fields are 84.9 degree.

Smith charts define a very important characteristic for a transceiver as it provides valuable information about impedances at different frequency point so that decision about the impedance matching can be taken. From Figures $17 \& 18$ it is clear that the RMT with the proposed innovative metamaterial structure provides better impedance matching at $2.259 \mathrm{GHz}$, when compared to RMT alone.

\section{Nicolson-Ross-Weir (NRW) Approach}

The values of permittivity and permeability affect the potential parameters like return loss and radiation pattern of a transceiver, this is the reason why these values are calculated. For obtaining the values of permeability and permittivity different methods can be used, some of them

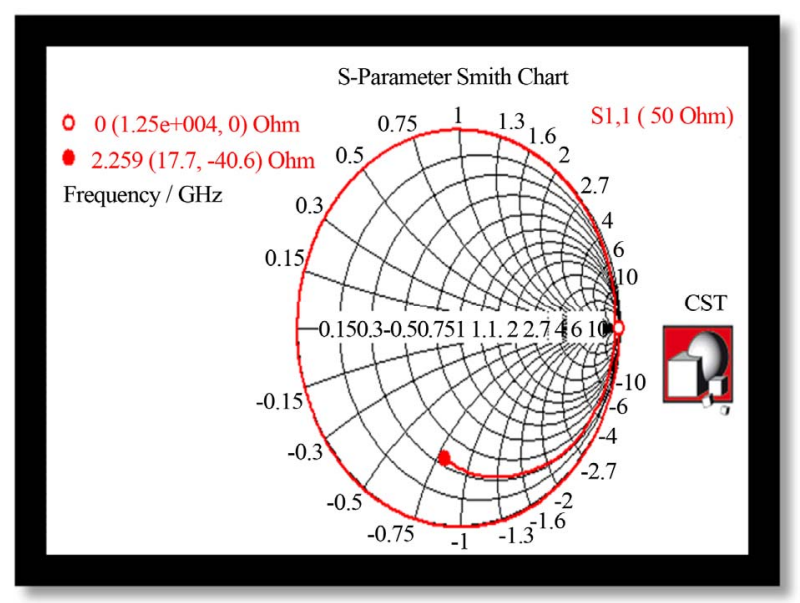

Figure 17. Smith chart of Rectangular microstrip transceiver.

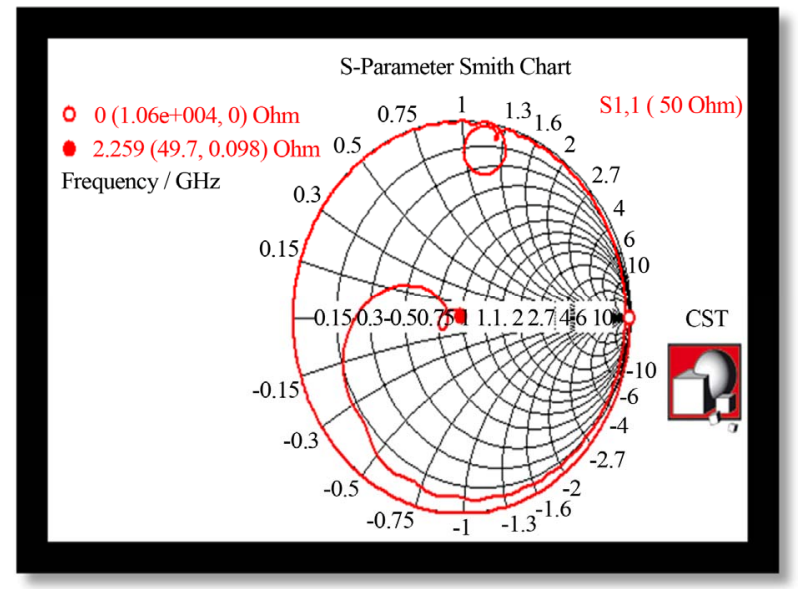

Figure 18. Smith chart of RMT with proposed metamaterial structure. are Nicolson-Ross-Weir (NRW), NIST iterative, Noniterative and Short circuit techniques. In this work Nicolson-Ross-Weir (NRW) technique [12-13] has been used to obtain the values of permittivity and permeability as this is a very popular technique to convert S-parameters due to the fact that this technique provides easy as well as effective formulation and calculation. All these methods discussed above required S-parameters for obtaining the values of permeability \& permittivity. Here in this work for extracting the S-Parameters, proposed metamaterial structure is placed between the two waveguide ports [14-16] at the left and right hand side of the $\mathrm{X}$ axis as shown in Figure 19. In Figure 19, Y-Plane is defined as Perfect Electric Boundary (PEB) and Z-Plane is defined as the Perfect Magnetic Boundary (PMB), which creates internal environment of waveguide. The simulated S-Parameters are then exported to Microsoft Excel Program for verifying the Double-Negative properties of the proposed metamaterial structure [17-19].

B. Equations used for calculating permittivity and permeability using NRW approach [20-22].

$$
\begin{array}{r}
\mu_{r}=\frac{2 \cdot c\left(1-v_{2}\right)}{\omega \cdot d \cdot i\left(1+v_{2}\right)} \\
\varepsilon_{r}=\frac{2 \cdot c\left(1-v_{1}\right)}{\omega \cdot d \cdot i\left(1+v_{1}\right)} \\
V_{1}=S_{11}+S_{21} \\
V_{2}=S_{21}-S_{11}
\end{array}
$$

where

$$
\begin{aligned}
& \varepsilon_{r}=\text { Permittivity } \\
& \mu_{r}=\text { Permeability } \\
& c=\text { Speed of Light } \\
& \omega=\text { Frequency in Radian } \\
& d=\text { Thickness of the Substrate } \\
& i=\text { Imaginary coefficient } \\
& V_{1}=\text { Voltage Maxima } \\
& V_{2}=\text { Voltage Minima }
\end{aligned}
$$

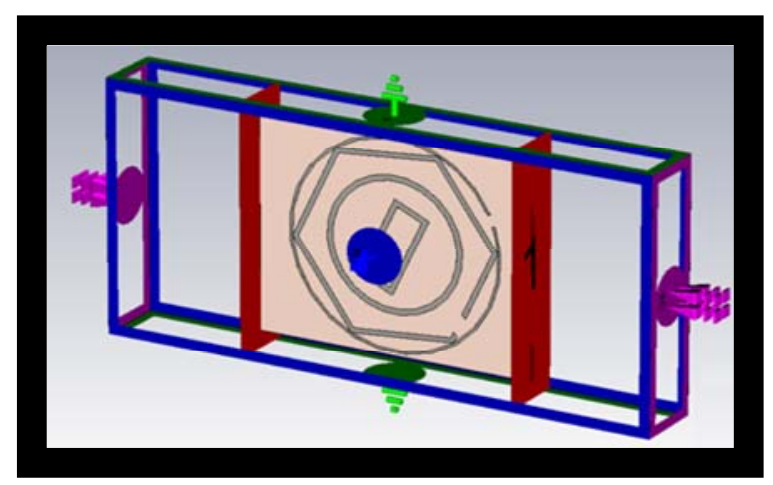

Figure 19. Proposed metamaterial structure between the two waveguide ports. 
For satisfying Double Negative property, the values of permeability and permittivity should be negative within the operating frequency range. The obtained values of these two quantities from the MS-Excel Program are given in Tables $2 \&$ 3, whereas Figures $20 \& 21$ show the graph between permeability vs. frequency and permittivity vs. frequency respectively.

The Tables generated for permittivity and permeability by using MS-Excel Software was too large, the Tables $2 \&$ 3 show the negative value of permeability and permittivity only in the frequency range $2.2499998-2.2649999 \mathrm{GHz}$.

Table 2. Sampled values of permeability at $2.259 \mathrm{GHz}$ calculated on ms excel software.

\begin{tabular}{ccc}
\hline $\begin{array}{c}\text { Frequency } \\
{[\mathrm{GHz}]}\end{array}$ & Permeability $\left[\mu_{r}\right]$ & $\operatorname{Re}\left[\mu_{r}\right]$ \\
\hline 2.2499998 & $-270.798587153409-112.375651867994 \mathrm{i}$ & -270.8 \\
2.2529995 & $-262.790056026946-112.871815587582 \mathrm{i}$ & -262.8 \\
2.256 & $-254.894924191312-113.10786541182 \mathrm{i}$ & -254.9 \\
2.2590001 & $-246.989518964166-113.062410329303 \mathrm{i}$ & -247 \\
2.2620001 & $-238.951915332999-112.766063352027 \mathrm{i}$ & -239 \\
2.2649999 & $-230.684613628889-112.297165820145 \mathrm{i}$ & -230.7 \\
\hline
\end{tabular}

Table 3. Sampled values of permittivity at $2.259 \mathrm{GHz}$ calculated on ms excel software.

\begin{tabular}{ccc}
\hline $\begin{array}{c}\text { Frequency } \\
{[\mathrm{GHz}]}\end{array}$ & Permittivity $\left[\varepsilon_{r}\right]$ & $\operatorname{Re}\left[\varepsilon_{r}\right]$ \\
\hline 2.2499998 & $-0.171922033221022-0.305191106496656 \mathrm{i}$ & -0.172 \\
2.2529995 & $-0.163397846483344-0.314433432234842 \mathrm{i}$ & -0.163 \\
2.256 & $-0.15445152683498-0.322675792751677 \mathrm{i}$ & -0.154 \\
2.2590001 & $-0.144420186288391-0.330172859997875 \mathrm{i}$ & -0.144 \\
2.2620001 & $-0.132763848247536-0.337457889150417 \mathrm{i}$ & -0.133 \\
2.2649999 & $-0.119185974821689-0.345248387298907 \mathrm{i}$ & -0.119 \\
\hline
\end{tabular}

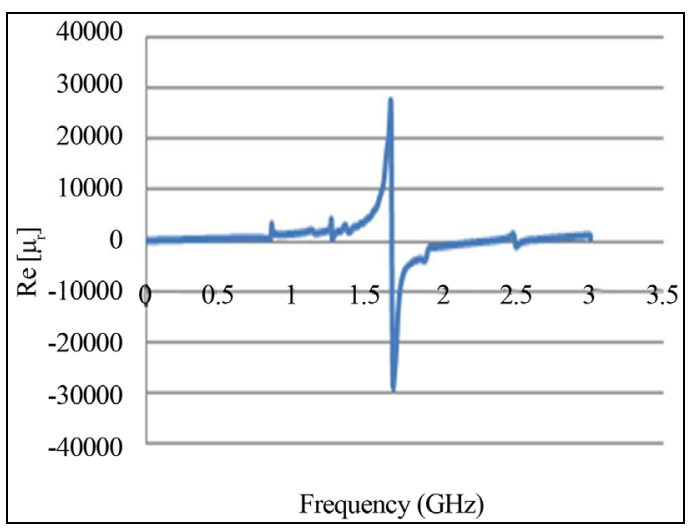

Figure 20. Permeability versus Frequency Graph.

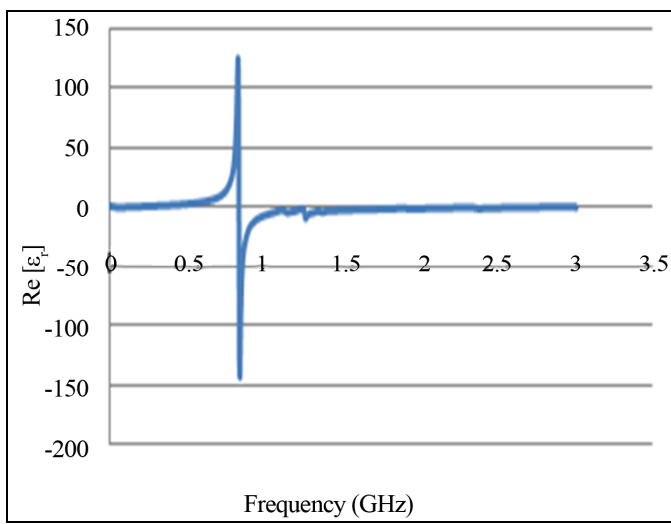

Figure 21. Permittivity versus Frequency Graph.

Further an additional arrangement is done for detection of obstacle, an op-amp IC-741 and comparator ICLM339MX is used to compare the return loss of transmitting and receiving RMT. An indicator IC-PT2395 is used to indicate difference of return loss and power of transmitting and receiving rectangular microstrip transceiver.

\section{Conclusion}

On the basis of the simulation results it is observed that the return loss obtained at the design frequency for the RMT with proposed innovative metamaterial structure is $-50.50 \mathrm{~dB}$ and bandwidth is $93.2 \mathrm{MHz}$. By simulating both the transceiver on CST-MWS, the return loss has significantly reduce by $391 \%$, the bandwidth has improved by $575 \%$ and efficiency is improved by $28 \%$ as shown in Figures 9-12. Smith Charts [23-25] in Figures $17 \& 18$ of both the transceiver shows the impedance at simulated frequency. This is remarkable improvement in ISM band, when compared to the results of RMT alone. It is clearly observed that the return loss, bandwidth, efficiency and directivity has improved significantly by incorporating the proposed metamaterial structure at $3.276 \mathrm{~mm}$ layer from the ground plane of the transceiver. By using the NRW method in MS-Excel Software, the negative permeability \& negative permittivity have been proved. The tables for permeability \& permittivity generated by the MS-Excel Software were too large, between the simulated frequency ranges $1-3 \mathrm{GHz}$. Therefore, Tables $2 \& 3$ show the negative values of permeability \& permittivity of the limited samples only in the frequency range $2.2499998-2.2649999 \mathrm{GHz}$. The Figures 20 \& 21 show the negative values of permeability \& permittivity of the proposed innovative metamaterial structure. Along with these improvements this structure satisfies double negative property within the simulated frequency range. By investigation it is found that there is difference between return loss and measured power of transmitter and receiver when an obstacle comes between transmitter and receiver. We set a false alarm condition 
and used a comparator to measure the difference between input and output signal.

\section{REFERENCES}

[1] T. Yamawaki, S. I. Yamano, Y. Katogi, T. Tamura and Y. Ohira, "Millimeter Wave Obstacle Detection Radar," FUJITSU Ten, Vol. 15, No. 15, 2000, pp. 10-22.

[2] V. Gupta and B. S. Dhaliwal, "Performance Enhancement of Recangular Microstrip Patch Antenna by Loading Complementary Split Ring Resonator in the Patch," International Journal of Electrical Engineering, Vol. 3, No. 1, 2011, pp. 141-143.

[3] V. G. Veselago, "The electrodynamics of substances with simultaneously negative values of $\mu$ and $\varepsilon$," Soviet Physics Uspekhi, Vol. 10, No. 4, 1968, pp. 509-514. doi:10.1070/PU1968v010n04ABEH003699

[4] N, Engheta and R. W. Ziolkowski, "Metamaterial Physics \& Engineering Explorations," Wiley-IEEE Press, Hoboken, 2006.

[5] J. B. Pendry, "Negative Refraction Makes a Prefect Lens," Physical Review Letters, Vol. 85, No. 18, 2000, pp. 3966-3969. doi:10.1103/PhysRevLett.85.3966

[6] J. B. Pendry, A. J. Holden, D. J. Robbins and W. J. Stewart, "Magnetism from Conductors and Enhanced Nonlinear Phenomena," IEEE Transactions on Microwave Theory and Techniques, Vol. 47, No. 11, 1999, pp. 20752081. doi: $10.1109 / 22.798002$

[7] D. R. Smith, W. J. Padilla, D. C. Vier, S. C. N. Nasser and S. Schultz, "Composite Medium with Simultaneously Negative Permeability and Permittivity," Physical Review Letters, Vol. 84, No. 18, 2000, pp. 4184-4187. doi:10.1103/PhysRevLett.84.4184

[8] B. -I. Wu, W. Wang, J. Pacheco, X. Chen, T. Grzegorczyk, J. A. Kong, "A Study of Using Metamaterials as Antenna Substrate to Enhance Gain," Progress in Electromagnetics Research, Vol. 51, No. 1, 2005, pp. 295-328. doi:10.2528/PIER04070701

[9] S. N. Burokur, M. Latrach and S. Toutain, "Theoretical Investigation of a Circular Patch Antenna in the Presence of a Left-Handed Mematerial," IEEE Antennas and Wireless Propagation Letters, Vol. 4, No. 3, 2005, pp. 183-186. doi:10.1109/LAWP.2005.850797

[10] C. A. Balanis, "Antenna Theory and Design," John Wiley and Sons, Inc., Hoboken, 1997.

[11] W. L. Stutzman and G. A. Thiele, "Antenna Theory and Design," 2nd Edition, John Wiley and Sons, Inc., Hoboken, 1998.

[12] H. A. Mazid, M. K. A. Rahim and T. Masri, "LeftHanded Metamaterial Design for Microstrip Antenna Application," IEEE International RF and Microwave Conference, 2008, pp. 218-221.

[13] R. W. Ziolkowski, "Design, Fabrication and Testing of Double Negative Metamaterials," IEEE Transactions on Antennas and Propagation, Vol. 51, No. 7, 2003, pp. 1516-1529. doi:10.1109/TAP.2003.813622

[14] S. Hrabar and J. Bartolic, "Backward Wave Propagation in Waveguide filled with Negative Permeability Meta Material," IEEE Antennas and Propagation Society International Symposium, Vol. 1, No. 1, 2003, pp. 110-113.

[15] S. Hrabar, G. Jankovic, B. Zivkovic and Z. Sipus, "Numerical and Experimental Investigation of Field Distribution in Waveguide filled with Anisotropic Single Negative Metamaterial," ICECom 18th International Conference on Applied Electromagnetics and Communications, Dubrovnik, 12-14 October 2005, pp. 1-4.

[16] S. Hrabar, J. Bartolic and Z. Sipus, "Waveguide Miniaturization Using Uniaxial Negative Permeability Metamaterial," IEEE Transaction on Antennas Propagation, Vol. 53, No. 1, 2005, pp. 110-119.

[17] H. A. Majid, M. K. A. Rahim and T. Marsi, "Microstrip Antenna Gain Enhancement Using Left-Handed Metamaterial Structure," Progress in Electromagnetics Research $M$, Vol. 8, No. 1, 2009, pp. 235-247.

[18] P. K. Singhal, B. Garg and N. Agrawal, "A High Gain Rectangular Microstrip Patch Antenna Using 'Different C Patterns' Metamaterial Design in L-Band," Advanced Computational Technique in Electromagnetics, Vol. 2012, 2012, Article ID: acte-00115.

[19] P. K. Singhal and B. Garg, "A High Gain \& Wide Band Rectangular Microstrip Patch Antenna Loaded With Interconnected SRR Metamaterial structure," International Journal of Engineering and Technology, Vol. 1, No. 3, 2012, pp. 335-346.

[20] P. K. Singhal and B. Garg, "Design and Characterization of Compact Microstrip Patch Antenna Using 'Split Ring' Shaped Metamaterial Structure," International Journal of Electrical and Computer Engineering, Vol. 2, No. 5, 2012, pp. 655-662.

[21] P. K. Singhal and B. Garg, "Improving Principle Design of Rectangular SRR based Metamaterial Structure with Negative $\mu$ and $\varepsilon$ for Characteristics of Rectangular Microstrip Patch Antenna," International Journal of Scientific Engineering and Technology, Vol. 1, No. 6, 2013, pp. 1-5.

[22] B. Garg and D. Saleem, "Analysis and Design of Innovative Double H Metamaterial Structure for Amelioration in Patch Antenna Parameters," Journal of Instrumentation Technology \& Innovations, Vol. 2, No. 3, 2012, pp. 1-8.

[23] B. Garg and D. Saleem, "Ameliorated RMPA using 'Squares Surrounded by Hexadecagon' Shaped Double Negative Metamaterial Structure in Ultra High Frequency (UHF) Band," American Journal of Engineering Science and Technology Research, Vol. 1, No. 1, 2013, pp. 1-9.

[24] B. Garg, D. Saleem and A. Das, "A Highly Efficient \& Directive Rectangular Microstrip Patch Transceiver Using Circular SRR Based Metamaterial Structure for Microwave and Wireless Communication Applications," International Journal of Information \& Computation Technology, Vol. 3, No. 9, 2013, pp. 710-713.

[25] B. Garg and D. Saleem, "Experimental Verification of Double Negative Property of LHM with Significant Improvement in Microstrip Transceiver Parameters in $\mathrm{S}$ Band," International Journal of Engineering Practical Research, Vol. 2, No. 2, 2013, pp. 64-70. 